The initial discrepancy in the association of the Au antigen and infectious hepatitis is almost certainly due, as Krugman has suggested, to difficulties in clinical differentiation between the two forms. Patients with hepatitis without a clear-cut history of parenteral inoculations are likely to be diagnosed as of the infectious type, but this type of infection may be transmitted by the parenteral route. And what is more important, the $\mathrm{SH}$, or serum, infection may be transmitted by the oral route. ${ }^{13}$ In this sense the patient's history can be misleading, but at all events the association of Au with $\mathrm{SH}$ antigen now seems firmly established. A report by Y. Cossart and co-workers ${ }^{15}$ in Britain showed that Australia-SH antigen had been identified by similar techniques in $40 \%$ of patients with acute viral hepatitis.

How does this fit in with other forms of liver disease? W. T. London and colleagues ${ }^{16}$ found no evidence of the $\mathrm{Au}$ antigen in other diseases affecting the liver, including cirrhosis, infectious mononucleosis, and hepatoma. Basically similar results have been reported by $R$. Wright and colleagues. ${ }^{17}$ They identified Au antigen in 46 out of 88 patients $(52 \%)$ with acute viral hepatitis, in 11 out of $29(38 \%)$ of those with prolonged viral hepatitis, and in 6 out of 24 $(25 \%)$ of those with chronic active hepatitis, and in only 3 of the remaining 248 patients with acute or chronic liver disease. G. L. Gitnick and co-workers found Au antigen in only 3 out of 31 patients with chronic active liver disease. ${ }^{18}$

Although the Au-SH antigen can be found more readily in the early weeks of the disease it can undoubtedly persist for long periods, ${ }^{1317}$ even for as long as 20 years. ${ }^{19}$ That the $\mathrm{Au}-\mathrm{SH}$ antigen is highly infectious there is little doubt. Studies $^{814}$ have shown it to be transmissible. Furthermore, workers in Britain ${ }^{20}$ have obtained positive tests for $\mathrm{SH}$ antigen from affected staff and patients after an outbreak of viral hepatitis in a haemodialysis unit. The antigen persisted for a longer period in affected patients and in one case was still positive after three years.

A study from Melbourne in this week's issue of the B.M.f. by Drs. J. D. Mathews and I. R. Mackay (page 259) indicates

1 British Medical fournal, 1969, 2, 645.

Allison, A. C., and Blumberg, B. S., Lancet, 1961, 1, 634

Blumberg, B. S., and Allison, A. C. in Proceedings of the Second International Congress of Human Genetics, p. 733. 1961.

4 Blumberg, B. S., Dray, S., and Robinson, J. C., Nature, 1962, 194, 656.

Blumberg, B. S., Bulletin of the New York Academy of Medicine, 1964, 40, 377 .

6 Blumberg, B. S., Alter, H. J., and Visnich, S., fournal of the American Medical Association, 1965, 191, 541.

Blumberg, B. S., Gerstley, B. J. S., Hungerford, D. A., London, W. T., and Sutnick, A. I., Annals of Internal Medicine, 1967, 66, 924.

8 Blumberg, B. S., Sutnick, A. I., and London, W. T., Bulletin of the New York Academy of Medicine, 1968, 44, 1566.

9 Blumberg, B. S., Sutnick, A. I., and London, W. T., fournal of the American Medical Association, 1969, 207, 1895.

10 Blumberg. B. S., Address at the London School of Hygicne and Tropical Medicine, 27 May 1969.

11 Prince, A. M., Proceedings of the National Academy of Sciences of the United States of America, 1968, 60, 814 .

12 Krugman, S., Giles, J. P., and Hammond, J., fournal of the American Medical Association, 1967, 200, 365.

13 Prince, A. M., Lancet, 1968, 2, 462 . New England fournal of Medicine, 1969, 281, 119.

15 Cossart, Y., Taylor, P. E., Vahrman, J., and Zuckerman, A. J., British Medical fournal, 1969, 3, 755.

16 London, W. T., Sutnick, A. I., and Blumberg, B. S., Annals of Internal Medicine, 1969 70, 55.

17 Wright, R., McCollum, R. W., and Klatskin, G., Lancet, 1969, 2, 117 .

18 Gitnick, G. L., et al., Lancet, 1969, 2, 285.

19 Zuckerman, A. J., and Taylor, P. E., Nature, 1969, 223, 81.

20 Turner, G. C., and White, G. B. B., Lancet, 1969, 2, 121.

21 Zuckerman, A. J., Nature, 1969, 223, 569.

22 Almeida, J. D., Zuckerman, A. J., Taylor, P. E., and Waterson, A. P. Microbios, 1969, 1, 117 .

23 Martley, J. W., Rowe, W. P., Bloom, H. H., and Turner, H. C., Proceedings of the Society for Experimental Biology and Medicine, 1964, 115, 414. that $\mathrm{Au}$ antigen was detected less often than might have been expected in their patients both in acute and in chronic cases. There appear to be differences in geographical incidence which are unlikely to be due to technical procedures, as most of the results reported have used reference sera from similar sources.

Another report in this week's B.M.F. (page 262) takes the story a stage further. This comes from work published by Dr. A. J. Zuckerman, Dr. Patricia E. Taylor, and Miss June D. Almeida, who have contributed much to our knowledge of the subject in this country. ${ }^{21}{ }^{22}$ On electron-microscopy these workers found virus-like structures displaying the characteristics of the coronavirus group. Furthermore, all the particles appeared to consist of antigen-antibody complexes. It must be stressed that this is a single observation and will have to be confirmed, but if confirmation is forthcoming this could be a discovery of the greatest significance. Mouse hepatitis virus belongs to the coronavirus group, and the finding of similar morphological structures in a human serum clearly calls for further study.

Antibodies to mouse hepatitis can be found in human sera, ${ }^{23}$ but it is not clear whether these result from infection with rodent excreta, as for example occurs with lymphocytic choriomeningitis virus, or by infection with a human serotype of the mouse hepatitis virus. The latter is a possibility that has to be considered in relation to the aetiology of acute infectious (IH) hepatitis. So far all attempts to isolate the viruses of hepatitis, both $\mathrm{IH}$ and $\mathrm{SH}$, have failed except in man but, as Zuckerman and his colleagues have shown by electron-microscopy studies, antigen-antibody complexes are often present. These may be responsible in part for the disease process; the antibody present may also inhibit virus growth in susceptible cells. This is exciting news and it is to be hoped that with the many new and specific techniques that have been developed we shall be hearing more of hepatitis antigens and the viruses responsible for hepatitis. If it can be proved that a corona-type virus is aetiologically related to infectious hepatitis, the next important step will be to isolate it by cultural methods. As well as being a step towards proving its identity this will be essential for developing measures of active immunization. Many have tried their hand at culturing the hepatitis viruses and all have so far failed. It will be interesting to see the outcome of further attempts based on this fascinating work.

\section{Neurological Complications of Influenza}

Epidemics of infectious disease are often accompanied by scattered cases of neurological complications, and the recent outbreak of influenza has been no exception. Meningitis caused by the Haemophilus influenzae has of course been recognized for years, with its particular dangers in early infancy, but epidemics of influenza have been of virus origin, with less tendency to cause meningeal inflammation. Viruses seem to cause neurological symptoms in two main ways. These are, firstly, by direct invasion of nervous tissue, such as in poliomyelitis or herpes simplex encephalitis; and, secondly, by starting some form of antigen-antibody reaction which may affect the brain, 
spinal cord, or peripheral nerve roots-for example, measles, glandular fever, and other exanthemata. Sometimes the same virus may be capable of producing both types of neurological disturbance, and there have been examples of this in the recent influenza outbreak.

Attacks of painful anyotrophy of the shoulder girdle and acute relapses in quiescent multiple sclerosis have been seen, but three other syndromes in particular have been noted during the present epidemic: an encephalitis or encephalopathy, a myelopathy, and an acute peripheral neuropathy resembling the Guillain-Barré syndrome. The encephalitis can occur as a result of direct virus invasion of the brain. After the preliminary symptoms of influenza, and when the patient is at the height of the illness, he develops, in addition to the headache and pyrexia which are common, drowsiness, confusion perhaps progressing to stupor and coma, with or without epileptic symptoms, but with little meningism and few outward signs of raised intracranial pressure. The cerebrospinal fluid at this stage is likely to show a considerable pleocytosis, equally polymorphonuclear and lymphocytic, and a moderate rise in protein; the sugar and chlorides are unaffected. Once coma has developed, the prognosis in this type of case may be poor, and it is not yet clear whether antibiotics and decompression greatly influence this.

Another form of encephalopathy occurs as the patient appears to have entered the recovery phase of the influenzal attack. He has a moderate recrudescence of headache, followed by confusion, drowsiness, and epileptic symptoms. The cerebrospinal fluid now may vary from showing little change to a moderate rise in lymphocytes and a rather greater rise in protein. The prognosis for these patients appears to be much better. But recurrence of encephalopathy after subsequent attacks of influenza is not unknown, almost as if the individual had some particular immunological susceptibility.

Myelopathy is the least common of the neurological complications and takes the form of a so-called transverse myelitis, Again during the recovery period, the patient has a day or two of root or girdle pain, usually in the thoracic region, which is followed by a very rapidly progressing paralysis and sensory loss in the lower limbs, with retention of urine. The limbs at first are flaccid; later they become hypertonic, with increased tendon jerks and extensor plantars, and there is usually a clear-cut upper level of sensory abnormality. The cerebrospinal fluid may show little evidence of acute inflammatory change and may be normal. Such patients often respond well to corticotrophin, whereas in the past many remained permanently paralysed.

In the present epidemic there have been many cases of polyneuropathy. During the stage of recovery the patient develops numbness in the extremities, followed by weakness of the proximal muscles of the arms and legs, which progresses within a few days to a flaccid paralysis of the limbs, absent tendon jerks, and tenderness of the muscles. The danger of the bulbar musculature or respiratory muscles becoming involved always exists, but most patients reach their plateau of disability before this stage. The cerebrospinal fluid shows a minimal rise in the number of cells but considerable increase of the protein. Corticotrophin given in the acute phase may considerably hasten what would in any case have been a spontaneous tendency to recovery.

These complications are uncommon, and some deaths apparently from encephalitis have been due not to viral invasion of the brain but to fulminating staphylococcal septicaemia. Failure of the patient to recover fairly rapidly after the acute phase if he is normally an active person should raise the question whether some neurological complication might have developed rather than the much commoner, and very real, post-influenzal depression.

\section{Antenatal Thromboembolism}

Thromboembolic disease has always been of particular concern to obstetricians and gynaecologists. Recently professional and public interest has centred on the role of synthetic oestrogens in the aetiology of these disorders. Because of the publicity given to the hazards of oral contraception it tends to be forgotten that, with the exception of abortion, pulmonary embolism is now the principal cause of maternal death. The risk of death from thromboembolism in pregnancy and the puerperium is greater than that from taking oral contraceptives. ${ }^{12}$

Reported maternal deaths from embolism ${ }^{2}$ decreased from 138 in $1952-5$ to 91 in 1964-6, a fall of $48 \%$ when the increase in birth rate is taken into account. But one feature of the detailed figures destroys any complacency that might be felt about them, for reported deaths from embolism during pregnancy rose from 4 in the early series to 24 in the later series, with a peak of 36 deaths in 1961-3. ${ }^{4}$ Since, with greater awareness, thromboembolic disease is now diagnosed and effective treatment is instituted earlier than formerly, the increased number of antenatal deaths from embolism implies an even greater increase in non-fatal disease

The reasons for this changing pattern are far from clear. Perhaps two factors might be pinpointed. The first is that many more patients are admitted to hospital for rest during the antenatal period than formerly. The second is that more patients at exceptional risk become pregnant and continue with the pregnancy. This aspect is emphasized in the report from Drs. J. Hirsh, J. F. Cade, and E. F. O'Sullivan in the B.M.F. this week (page 270). Out of 14 patients treated with anticoagulants during pregnancy three had prosthetic heart valves, one had mitral stenosis and pulmonary hypertension, and three others had a previous history of thromboembolic disease.

Deep-vein thrombosis may develop insidiously, and $50-80 \%$ of affected patients have no physical signs of the condition. ${ }^{5}$ Ancillary methods of investigating it seem to be of value chiefly in the confirmation of suspected cases of thrombosis. ${ }^{5}$ Techniques involving the use of ionizing radiations are best avoided in pregnancy, but recently the value of ultrasonics in the detection of major venous occlusions has been shown. ${ }^{6}$ With refinements of technique and apparatus these methods may become more useful in

1 Vessey, M. P., and Weatherall, J. A. C., Lancet, 1968, 2, 94.

Report on Confidential Inquiries into Maternal Deaths in England and Wales, 1964-66. H.M.S.O., London, 1969.

3 Report on Confidential Inquiries into Maternal Deaths in England and Wales, 1952-54. H.M.S.O., London, 1957.

Report on Confidential Inquiries into Maternal Deaths in England and Wales, 1961-63. H.M.S.O., London, 1966.

5 Browse, N., British Medical fournal, 1969, 4, 676

6 Evans, D. S., and Cockett, F. B., British Medical fournal, 1969, 2, 802.

7 Villasanta, U., American fournal of Obstetrics and Gynecology, 1965, 93, 142 .

8 Taylor, J. J., Postgraduate Medical fournal, 1965, 41, 80.

9 Kerber, I. J., Warr, O. S., and Richardson, C., fournal of the American Medical Association, 1963, 203, 223.

10 Vigran, I. M., Clinical Anticoagulant Therapy. London, Kimpton, 1965. 